\title{
Silicon isotopes reveal a decline in oceanic dissolved silicon driven by biosilicification: a prerequisite for the Cambrian Explosion?
}

\author{
YAN YE ${ }^{1,2}$, DR. PATRICK J. FRINGS ${ }^{3}$, FRIEDHELM VON \\ BLANCKENBURG $^{3,4}$ AND QINGLAI FENG ${ }^{1,2}$ \\ ${ }^{1}$ China University of Geosciences \\ ${ }^{2}$ State Key Laboratory of Geological Processes and Mineral \\ Resources, China University of Geosciences \\ ${ }^{3}$ GFZ German Research Centre for Geosciences \\ ${ }^{4}$ Freie Universität Berlin \\ Presenting Author: yeyan@cug.edu.cn
}

The Early Phanerozoic witnessed one of the most important events in Earth history - the Cambrian Explosion. There is also a consensus that at roughly the same time oceanic dissolved silicon (DSi) concentrations decreased from close to saturation to somewhere below saturation. Yet the timing and magnitude of the putative DSi decrease, and any relationship with biological innovations, remain poorly known.

Here, we study the widespread chert formed during the Ediacaran-Cambrian (E-C) transition (ca. 551-522 Ma) on the Yangtze Block, South China. Major and trace element geochemical proxies (Al/(Al+Fe+Mn), $\mathrm{Eu} / \mathrm{Eu}^{*}$ and $\left.\mathrm{Ge} / \mathrm{Si}\right)$ suggest the silicon for the chert is predominantly sourced from seawater, and most likely precipitated via adsorption on organic matter and uptake by silica-secreting organisms. New and compiled bulk-rock silicon isotope data from six sections spanning the E-C boundary show a divergence in $\delta^{30} \mathrm{Si}$ values at ca. $533 \mathrm{Ma}$, that is, the $\delta^{30} \mathrm{Si}$ range (maximum-minimum) increases from $0.3 \sim 1.1 \%$ to $1.1 \sim 1.6 \%$. Using mass-balance arguments, we interpret this as evidence that the radiation of siliceous sponges and radiolarians contributed to a decrease in oceanic DSi concentrations. A DSi decline would have caused a more heterogenous distribution of ocean $\mathrm{DSi}$, and so $\delta^{30} \mathrm{Si}$ in individual sections would be more sensitive to localized and/or short-term fluctuations in the silicon isotope fractionations associated with chert formation. This interpretation is corroborated by a simple box-model, which predicts a ca. $80 \%$ decline in DSi concentrations, under reasonable assumptions of sponge productivity.

Lower oceanic DSi may reduce the effort needed to maintain intracellular Si concentrations below the level at which harmful Si precipitation in organismal cytoplasm occurs. This energy can be reallocated to other metabolic pathways of new functional types, especially the establishment of suspension-feeding communities that triggered Phanerozoic-type mixground ecology. Therefore, the early appearance of silicifiers ( $\sim 540-530$ $\mathrm{Ma})$, by altering the Si cycle, may have promoted the main stage ( $\sim 520 \mathrm{Ma})$ of Cambrian Explosion. 